\title{
Calibration of aerodynamic roughness over the Tibetan Plateau with Ensemble Kalman Filter analysed heat flux
}

\author{
J. H. Lee ${ }^{1,2}$, J. Timmermans ${ }^{2}$, Z. Su${ }^{2}$, and M. Mancini ${ }^{1}$ \\ ${ }^{1}$ Politecnico di Milano, Piazza Leonardo da Vinci 32, Milano, Italy \\ ${ }^{2}$ ITC, Geo-Information Science and Earth Observation of the University of Twente, Enschede, The Netherlands
}

Correspondence to: M. Mancini (marco.mancini@polimi.it)

Received: 5 March 2012 - Published in Hydrol. Earth Syst. Sci. Discuss.: 19 April 2012

Revised: 27 August 2012 - Accepted: 19 October 2012 - Published: 20 November 2012

\begin{abstract}
Aerodynamic roughness height $\left(Z_{\text {om }}\right)$ is a key parameter required in several land surface hydrological models, since errors in heat flux estimation are largely dependent on optimization of this input. Despite its significance, it remains an uncertain parameter which is not readily determined. This is mostly because of non-linear relationship in Monin-Obukhov similarity (MOS) equations and uncertainty of vertical characteristic of vegetation in a large scale. Previous studies often determined aerodynamic roughness using a minimization of cost function over MOS relationship or linear regression over it, traditional wind profile method, or remotely sensed vegetation index. However, these are complicated procedures that require a high accuracy for several other related parameters embedded in serveral equations including MOS. In order to simplify this procedure and reduce the number of parameters in need, this study suggests a new approach to extract aerodynamic roughness parameter from single or two heat flux measurements analyzed via Ensemble Kalman Filter (EnKF) that affords non-linearity. So far, to our knowledge, no previous study has applied EnKF to aerodynamic roughness estimation, while the majority of data assimilation study have paid attention to updates of other land surface state variables such as soil moisture or land surface temperature. The approach of this study was applied to grassland in semi-arid Tibetan Plateau and maize on moderately wet condition in Italy. It was demonstrated that aerodynamic roughness parameter can be inversely tracked from heat flux EnKF final analysis. The aerodynamic roughness height estimated in this approach was consistent with eddy covariance method and literature value. Through a calibration of this parameter, this adjusted the sensible heat previously overestimated and latent heat flux previously underestimated by the
\end{abstract}

original Surface Energy Balance System (SEBS) model. It was considered that this improved heat flux estimation especially during the summer Monsoon period, based upon a comparison with precipitation and soil moisture field measurement. For an advantage of this approach over other previous methodologies, this approach is useful even when eddy covariance data are absent at a large scale and is time-variant over vegetation growth, as well as is not directly affected by saturation problem of remotely sensed vegetation index.

\section{Introduction}

\subsection{The Tibetan plateau}

The Tibetan Plateau plays a major role on land surface circulation all over the Asian continents (Ma et al., 2009). Hence, this region is also called the "Third Pole" (along with the North and South Pole) and has been paid much attention from a broad range of scientific community. This study is based upon turbulent meteorological data measured at the BJ station located in the Naqu site, one of Tibetan Observation and Research Platform (TORP) under the frame of GEWEX (Global Energy and Water Cycle Experiment) of World Meteorological Organization(WMO), consisting of 21 research and 16 observation stations (Ma et al., 2009). In this Naqu region, vertical gradients of temperature and humidity in the atmospheric boundary layer (ABL) exhibits a dramatic change around onsets of Monsoon period (Sun et al., 2006, 2007). As ground surface temperature increases with a decrease in air temperature, convective activity and sensible heating is accelerated, resulting in Monsoon climate (Wen et al., 2010). 
Around this time, local grass proliferates and leaf area index (LAI) starts increasing at the onsets of Monsoon, and decreases in winter, while albedo conversely alters. Accordingly, aerodynamic roughness parameters in this site make a seasonal change, being governed by various aerodynamic and thermodynamic characteristics. Aerodynamic roughness over the Tibetan plateau was previously explored by various approaches such as traditional wind profile method using eddy covariance instruments, flux-variance method, and vegetation index (Choi et al., 2004; Ma et al., 2002, 2005, 2008; Su, 2002, 2005; Yang et al., 2003, 2008).

\subsection{Uncertainty associated with determination of aerodynamic roughness}

Aerodynamic roughness height is a significant parameter to a variety of models such as weather prediction model (e.g. AROME), land surface model (e.g. NOAH, CLM), or other hydrological models. Consequently, errors in these parameters can be propagated through models and become a major error source in the output of those models (Chen et al., 2010; Zeng et al., 2007).

In general, aerodynamic roughness height is referred to as the height where the logarithmic wind profile reaches zero. If eddy covariance data are available at local scale, an independent wind profile method can be employed to estimate this height using following formulation: $Z_{\mathrm{om}}=Z \cdot e^{-\frac{k u}{u^{*}}-\Psi_{\mathrm{m}}}$. Here, $k$ is von Karman constant; $u$ is horizontal velocity; $u^{*}$ is friction velocity; $Z$ is measurement height; and $\Psi_{\mathrm{m}}$ is atmospheric stability correction as a function of Obukhov length (Ma et al., 2008). Estimation of aerodynamic roughness is usually performed under neutral (i.e. $\Psi_{\mathrm{m}}=0$ ) or nearneutral condition when turbulent transfer coefficient for humidity and temperature is considered to be equivalent, while other researchers suggest to include all the atmospheric stability conditions or to use turbulent data under unstable and highly convective condition only (Kohsiek et al., 1993; Ma and Daggupaty, 1999; Scanlon et al., 2001; Yang et al., 2003). However, in some cases, atmospheric stability is not readily adjusted by Monin-Obukhov similarity (MOS), on account of some measurement error or inapplicable assumption of horizontal surface homogeneity - for example, in case of sparsely vegetated area, less equilibrated boundary layer can be developed above the surface (Foken and Wichura, 1996; Prueger et al., 2004). This produces high standard deviation and scatteredness in aerodynamic roughness height estimates (Yang et al., 2008).

To circumvent these uncertainties in momentum flux attributes and to infer aerodynamic roughness height at large scale from geometric characteristics, several previous studies employed remotely sensed Vegetation Index (VI) (e.g. LAI or NDVI) (Olioso et al., 2002; Richter and Timmermans, 2009; Su et al., 2001; Timmermans et al.,2011). However, VIs also have a degree of uncertainty in determination of the aerodynamic roughness. First, VI tends to saturate at high

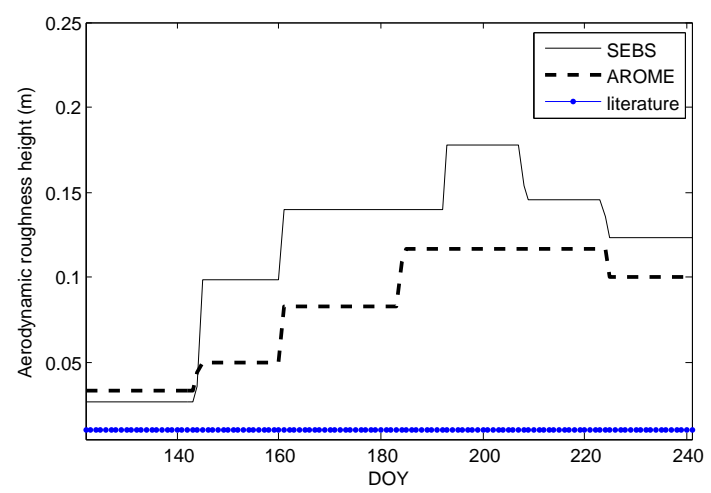

Fig. 1. Bias in aerodynamic roughness height estimation over short grassland around BJ station during experimental period of this study: original SEBS model, literature (Beljaars et al., 1983) and AROME model (MODIS LAI/6).

LAI values above 3 to 4 . Due to reflection, cloud effect and landscape misclassification, remotely sensed LAI is sometimes attenuated by $41 \%$, losing vertical characteristics of vegetation (Yang et al., 2006; Yao et al.,2008). Additionally, according to nutrient nourishment or vegetation species, vegetation has different sensitivities to VI so that each different vegetation species presents different ranges of maximum and minimum VI over similar aerodynamic roughness height. For instance, some tall coniferous trees have a similar LAI level to low crops, while some low crops such as rice indicate 5 to 6 high LAI values over 1 to $2 \mathrm{~m}$ high canopy (Chen and Yang, 2005). In case of deciduous forest whose chlorophyll contents diminish in the fall, LAI decreases such that aerodynamic roughness can be underestimated unlike tropical evergreen forest. Therefore, parameterization relying on remotely sensed Vegetation Index only is sometimes not agreeable with field observed aerodynamic roughness, especially as it is very difficult to retrieve a canopy height with remote sensing measurements alone. This uncertainty stemming from the use of VI can be propagated into the roughness height estimation, which can lead to a large error in heat flux estimation.

To illustrate the bias associated with several aerodynamic roughness estimations, Fig. 1 was provided. Not only does remotely sensed VI have uncertainty as noted above but a literature value also contains a degree of uncertainty arising from low temporal variation. In detail, although MODIS NDVI in BJ station has changed from 0.17 to 0.53 and MODIS LAI has evolved from 0.2 to 0.7 for day of year 140 through 240 during experimental period of this study, aerodynamic roughness from literature or landscape map remained time-invariant as shown in Fig. 1, neglecting its vegetation effect by Monsoon climate. In addition, AROME (as function of LAI) and SEBS model (as a function of LAI and NDVI) overestimated this parameter by 5 times or more, because of several reasons such as model structure or VIs problem. Over or underestimation of fetch size may also 
have an influence on aerodynamic roughness estimation error. From a slightly different perspective, Yang et al. (2003) argued about the use of VI that heat transfer is affected by ground surface characteristic such as temperature difference between land surface and air or momentum flux more than vegetation effect, according to a dual-source model study over energy partition. Tsuang et al. (2003) attempted to find optimal aerodynamic roughness in MOS theory using a linear regression between momentum velocity or potential temperature and displacement height, while Ma et al. (2000) minimized a cost function over potential temperature, wind velocity, and heat flux (Yang et al., 2003). However, this approach is affected by measurement or estimation errors of several associated parameters (i.e. wind velocity, stability correction parameter, potential temperature, or Obukhov length etc.) involved in MOS theory. For example, Obukhov length estimated by MOS equation iteration has sometimes a discrepancy from eddy covariance methods.

Thus, as a useful method, this study suggest data assimilation to deal with various errors. However, there were few previous studies who have employed data assimilation for parameter estimation, although several previous studies applied data assimilation for soil moisture update as a state variable (Montaldo et al., 2001, 2007). Moradkhani et al. (2005) demonstrated a dual state-parameter estimation. It first perturbed several input parameters to be considered time-variant. Out of five parameters to be examined, quick-flow tank parameter was best converged in data assimilation. On the contrary, other four parameters were less identified although it carried out data assimilation with data collected over three years. After determining input parameters via EnKF, those inputs were further used to update the state variable. Because state variables were considered unobservable in this previous study, accuracy was indirectly assessed by stream flow forecasting. Goegebeur and Pauwels (2007) compared the performance of extended Kalman filter with Parameter ESTimation (PEST) method that minimizes an objective function as briefly introduced above. The latter is different from the extended Kalman filter approach minimizing a square error with observation. After applying these two algorithms into a conceptual rainfallrunoff model, this study concluded that the extended Kalman filter performed better than the objective function minimization methods, since it can accommodate high observation error, a low frequency of observation update, and erroneous initial parameters. Pauwels et al. (2009) further employed the extended Kalman filter for parameter estimation by combining a land surface model and remote sensing (i.e. SAR surface soil moisture). This study estimated three soil hydraulic model parameters using TOPLATS (TOPMODEL based Land Atmosphere Transfer Scheme) - i.e. saturated hydraulic conductivity, pore size distribution index, and bubbling pressure. After a calibration of these parameters, model output reached an agreement with SAR retrieved surface soil moisture. However, one of the well-known drawbacks in the extended Kalman filter is that when a system is highly nonlinear, as in hydrological applications, the extended Kalman filter tends to be unstable (Moradkhani et al., 2005). This instability or divergence of the extended Kalman filter originates from demands of high computational cost due to error covariance propagation or from insufficient approximation simplified by ignoring the higher order of derivatives and just using the first order Taylor series of a linear model. On the other hand, the ensemble Kalman filter can deal with a nonlinear system with better stability (Evensen, 2004; Margulis et al., 2002; Moradkhani et al., 2005; Reichle et al., 2002; Reichle, 2008). Another advantage of ensemble Kalman filter is that it is not required to estimate a priori model covariance for updating, since it uses model ensemble (Moradkhani et al., 2005). In theory, it requires the joint Gaussian probability distribution between measurements and propagated states based upon Bayes theorem. However, in several cases of nonlinear hydrological applications, it was reported that the ensemble Kalman filter can also handle non-Gaussian or nonadditive noise (Margulis et al., 2002; Dunne et al., 2005).

This study attempted to introduce a new application of data assimilation into a hydrological study. With respect to a previous study, a new aspect and advantage of this study is (1) to demonstrate an operational frame applying EnKF into determining the parameter (i.e. aerodynamic roughness height) less explored in previous data assimilation study; (2) to conduct a calibration requiring a smaller number of parameters - only one estimate, sensible heat flux used in EnKF as a true field - in comparison with a cost function minimization approach; (3) to be less affected by the saturation problem of remotely sensed vegetation index in estimation of aerodynamic roughness; (4) to be time-variant in comparison with literature values which stay constant regardless of Monsoon dynamics; (5) to be applicable when eddy covariance data are not available.

This study suggested that ensemble kalman filter provides a versatile and relatively more simple tool to extract appropriate aerodynamic roughness height from single or two heat flux. Heat flux model states were fitted against observations via EnKF. They were inversely tracked back to the input ensemble members that yielded heat flux EnKF final analysis. Detail methods were described in following sections, respectively. In result, aerodynamic roughness height estimated in this study was inserted into an energy balance model to show its impact. Those heat flux outcomes were compared before and after calibration. Additionally, parameter estimated by this approach was compared with other approaches such as eddy covariance or vegetation index formulation.

\section{Methods}

EnKF was employed to compensate for the limitations of each model physics with different error structures by merging the model estimates contaminated by updating model 


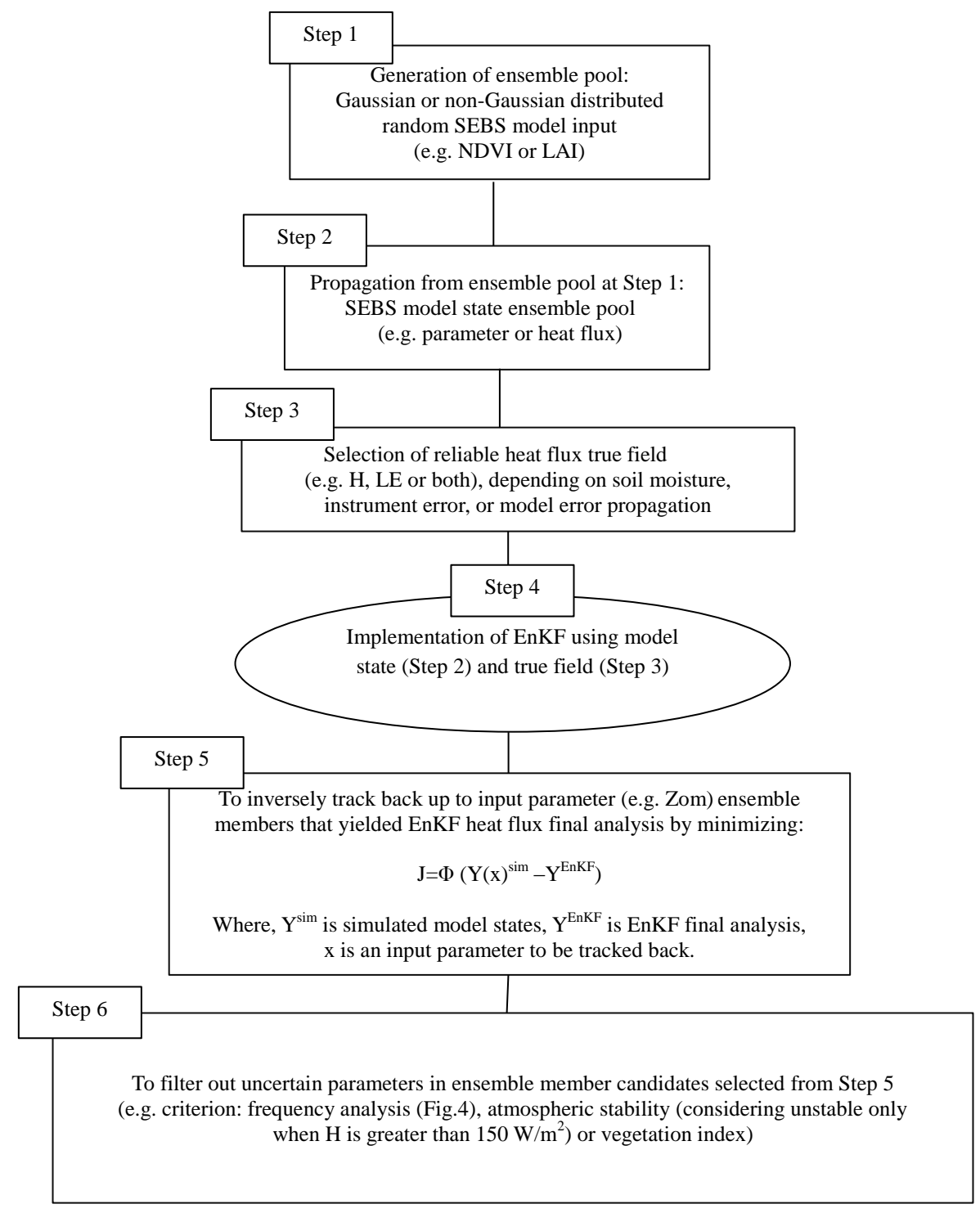

Fig. 2. Conceptual diagram for determination of aerodynamic roughness via EnKF.

states presumably deteriorated by aerodynamic roughness input errors, but independent from assumption of energy balance closure with the field observation independent from aerodynamic roughness input errors, but biased by the assumption of energy balance closure. In other words, field measured heat flux estimates were employed as EnKF true field, while hydrological model estimates played a role of relating optimal heat flux to initial parameter input. Brief concept was introduced in Fig. 2. Each of the blocks was explained in following sections.

\subsection{Field observation: Bowen Ratio Energy Balance (BREB)}

During the experimental period, eddy covariance data were unavailable at the BJ station in Naqu sites in 2006. Instead, the Bowen Ratio Energy Balance (BREB) method was employed, based upon a previous validation study with eddy covariance data (van der Velde et al., 2009). Several previous studies also employed the BREB over the Tibetan Plateau in a long-term estimation (Liu et al., 2009; Lu et al., 2012). By this, it was considered that BREB is capable of estimate semi-arid climate heat flux in given temperature and vapour pressure levels, since they were previously agreeable with eddy covariance data in study above. In addition to this, since error source of BREB estimates stem from the gradient of temperature or vapour pressure, those errors were filtered out in this section in order to decrease the uncertainty. 
BREB estimates heat flux using temperature and vapor pressure gradient as follows:

Bowen $\operatorname{ratio}(\beta)=\gamma \frac{T_{1}-T_{2}}{e_{1}-e_{2}}$

where, $e_{1}$ and $e_{2}$ are vapor pressure measurements [kPa] observed at two different levels, while $T_{1}$ and $T_{2}$ are air temperature $[\mathrm{K}]$ measured at the same measurement heights $\left(Z_{1} / Z_{2}>4\right)$ and $\gamma$ is psychometric constant $\left[\mathrm{kPa} \mathrm{K}^{-1}\right]$. This Bowen ratio is further used to calculate heat flux from surface energy balance.

$\lambda E=\frac{R_{\mathrm{n}}-G_{\mathrm{o}}}{1+\beta} H=\frac{\beta}{1+\beta}\left(R_{\mathrm{n}}-G_{\mathrm{o}}\right)$

where,

$G_{\mathrm{o}}=k_{\mathrm{h}} \frac{T_{\text {skin }}-T_{\mathrm{sl}}}{\mathrm{d} z}$

$\lambda E$ is latent heat. $H$ is sensible heat. Soil heat flux $\left(G_{\mathrm{o}}\right)$ was determined by thermal conductivity $k_{\mathrm{h}}\left[\mathrm{W} \mathrm{mK}{ }^{-1}\right]$ as a function of soil moisture contents $\left[\mathrm{m}^{3} \mathrm{~m}^{-3}\right] . z$ is soil depth, while $T_{\text {skin }}$ is surface temperature. $T_{\mathrm{sl}}$ is soil temperature at depth of $0.05 \mathrm{~m}$. Net radiation was combined from inward and outward short wave radiation as well as inward and outward long wave radiation, whose component was measured from a radiation sensor (van der Velde, 2010).

In EnKF, the key to success is the quality of observations used as a true field (a priori). Therefore, to acquire reliable geophysical information representing a characteristic of parameter of interest (i.e. $Z_{\mathrm{om}}$ ), this study rejected most of the uncertain and irrelevant measurement data, according to following criteria:

1. Turbulent data with $\beta$ below -0.7 were excluded, to forbid latent heat sign error occurring during night time (Perez et al., 1999; Tsuang et al., 2003).

2. Heat flux values with incorrect sign were further excluded, according to flux and gradient relationship: latent heat has an opposite sign with respect to specific humidity gradient (Ohmura, 1982). Accordingly, entire data showed negative humidity gradient, suggesting positive latent heat (evaporation).

3. To select turbulent characteristics governing aerodynamic momentum roughness, wind measurement data with low velocity $\left(U_{2}\right)$ less than $1 \mathrm{~m} \mathrm{~s}^{-1}$ and small wind velocity gradient $\left(U_{1}-U_{2}<0.3 \mathrm{~m} \mathrm{~s}^{-1}\right)$ as well as low friction velocity were also neglected (Liu and Foken, 2001).

4. Data with small temperature gradient $\left(T_{2}-T_{1}<0.1 \mathrm{~K}\right)$ were discarded (Yang et al., 2003).In arid region such as Naqu sites, temperature gradient is considered more important than vapor pressure gradient. Vapor pressure is usually so small on dry condition that it might be readily subject to measurement error.
5. Sensible heat fluxes below $10 \mathrm{~W} \mathrm{~m}^{-2}$ were also excluded to capture convective condition (Yang et al., 2003).

Consequently, this data filtering resulted in sensible heat on free convective turbulent condition ranged above $50 \mathrm{~W} \mathrm{~m}^{-2}$.

\subsection{Model states: Surface Energy Balance System (SEBS)}

SEBS was developed to estimate atmospheric fluxes on the large to global scale using satellite earth observation data. As an input, it requires land surface parameters such as canopy height, emissivity, albedo and LAI, and meteorological turbulent data such as wind speed and humidity as well as radiation. Unlike energy balance residual methods, SEBS estimates sensible heat flux from non-linear MOS equations, while it determines latent heat from evaporation fraction. Evapotranspiration product of this SEBS baseline algorithm is available to general public (www.wacmos.com).

\subsubsection{Roughness lengths}

Displacement height $d_{0}$, aerodynamic $Z_{\text {om }}$ and thermal roughness lengths $Z_{\text {oh }}$ were estimated as followed (Massman, 1997; Su et al., 2001; Su, 2002).

$$
\begin{aligned}
& d_{0}=h_{\mathrm{c}}\left(1-\frac{1}{2 n_{\mathrm{ec}}} \times\left(1-\exp \left(-2 n_{\mathrm{ec}}\right)\right)\right) \\
& z_{\mathrm{om}}=h_{\mathrm{c}}\left(1-\frac{d_{0}}{h_{\mathrm{c}}}\right) \exp \left(-k \frac{u\left(h_{\mathrm{c}}\right)}{u^{*}}\right)
\end{aligned}
$$

where, $h_{\mathrm{c}}$ is canopy height estimated as a function of MODIV NDVI. Within-canopy extinction is formulated below.

$n_{\mathrm{ec}}=\frac{C_{\mathrm{d}} \mathrm{LAI}}{2}\left(\frac{u\left(h_{\mathrm{c}}\right)}{u^{*}}\right)^{2}$

Here, $C_{\mathrm{d}}$ is drag coefficient of foliage, while LAI is leaf area index. LAI was formulated as a function of MODIS NDVI to be propagated through model. $u\left(h_{\mathrm{c}}\right) / u^{*}$ was determined from Massman methods (Su et al., 2001). Additionally, by $k B^{-1}$ values for mixed canopy and soil, thermal roughness height is related to aerodynamic roughness height (Choudhury and Monteith, 1988).

$k B^{-1}=\log \left(\frac{z_{\mathrm{om}}}{z_{\mathrm{oh}}}\right)$

Here, $k B^{-1}$ is an excess resistance to heat transfer. It is expressed a function of roughness Reynolds number for bare soil surface, while it is estimated from several other parameters such as leaf heat transfer coefficient, fractional canopy coverage, and within canopy wind speed profile extinction coefficient for canopy landscape (Su, 2005). Accordingly, 
in this study, if NDVI was under or overestimated, LAI, $u\left(h_{\mathrm{c}}\right) / u^{*}$, displacement height, and aerodynamic roughness height were designed to be consecutively propagated as formulated above.

\subsubsection{Evaporation fraction}

The roughness height for heat and momentum (resp. $Z_{\mathrm{oh}}$ and $Z_{\mathrm{om}}$ ) determined as above are used in MOS relationship to estimate sensible heat, and aerodynamic resistance (Su, 2002). Sensible heat estimated in this way is further exploited to determine latent heat. In SEBS, latent heat is calculated using evaporative fraction, the ratio of heat fluxes on hypothetical condition (sensible heat on the hypothetical wet/dry condition, and residual latent heat on wet condition) to available energy ( $\mathrm{Su}, 2002)$.

$\lambda E=\Lambda\left(R_{\mathrm{n}}-G_{\mathrm{o}}\right)$

where, evaporative fraction is

$\Lambda=\frac{\Lambda_{\mathrm{r}} \lambda E_{\mathrm{wet}}}{R_{\mathrm{n}}-G_{\mathrm{o}}}$

Here, relative evaporation is

$\Lambda_{\mathrm{r}}=1-\frac{H-H_{\mathrm{wet}}}{H_{\text {dry }}-H_{\mathrm{wet}}}$

and

$\lambda E_{\mathrm{wet}}=R_{\mathrm{n}}-G_{\mathrm{o}}-H_{\mathrm{wet}}$

Under the dry condition, $H_{\text {dry }}$ in Eq. (2-7) is directly estimated by approximation of $R_{\mathrm{n}}-G_{\mathrm{o}}$ assuming latent heat is zero $\left(\lambda E_{\mathrm{dry}}=0\right)$. Sensible heat on wet condition $H_{\mathrm{wet}}$ in Eq. (2-7) is formulated as followed.

$H_{\mathrm{wet}}=\left[\left(R_{\mathrm{n}}-G_{\mathrm{o}}\right)-\frac{C_{\mathrm{p}} \rho_{\mathrm{air}}}{r_{\mathrm{a}}} \frac{\left(e_{\mathrm{sat}}-e_{\mathrm{a}}\right)}{\gamma}\right] \frac{\gamma}{\Delta+\gamma}$

where,

$r_{\mathrm{a}}=\frac{1}{k U^{*}}\left[\ln \left(\frac{z-d_{0}}{z_{\mathrm{oh}}}\right)-\Psi_{\mathrm{h}} \frac{\left(z-d_{0}\right)}{L_{\mathrm{w}}}+\Psi_{\mathrm{h}}\left(\frac{z_{\mathrm{oh}}}{L_{\mathrm{w}}}\right)\right]$

Here, $\rho_{\text {air }}$ is the density of dry air $\left[\mathrm{kg} \mathrm{m}^{-3}\right] . C_{\mathrm{p}}$ is heat capacity $\left[\mathrm{J} \mathrm{kgK}^{-1}\right] . e_{\mathrm{a}}$ is actual vapour pressure $[\mathrm{Pa}]$, while $e_{\text {sat }}$ is saturation vapour pressure at reference height $[\mathrm{Pa}] . r_{\mathrm{a}}$ is aerodynamic resistance to heat transfer $\left[\mathrm{s} \mathrm{m}^{-1}\right] . L_{\mathrm{w}}$ is wet-limit stability length. $\Delta$ is the rate of change of saturation vapour pressure with temperature, while $\gamma$ is the psychometric constant $\left[\mathrm{Pa} \mathrm{K}^{-1}\right]$.

\subsection{Implementation of Deterministic Ensemble Kalman Filter (DEnKF)}

Ensemble Kalman filter appearing in this study implies Deterministic Ensemble Kalman Filter. DEnkF was chosen in order to update ensemble SEBS heat flux pool with BREB estimates considered as "a priori". Among other Kalman filters, DEnKF was selected because it does not require significant perturbation in observation of latent and sensible heat. Instead, error of heat flux is considered in data assimilation by adjusting a variance of observation. In other words, the term of observation perturbation in traditional Kalman filter analysis is set to zero (Sakov and Oke, 2008; Reichle, 2008).

$X_{i}^{\mathrm{a}}=X_{i}^{\mathrm{f}}+K\left(\boldsymbol{d}+\boldsymbol{D}_{i}-\mathbf{H} X_{i}^{\mathrm{f}}\right)=X_{i}^{\mathrm{f}}+K\left(\boldsymbol{d}-\mathbf{H} X_{i}^{\mathrm{f}}\right)$

where, $X_{i}^{\mathrm{a}}$ is analysis. $X_{i}^{\mathrm{f}}$ is forecast. $K$ is Kalman gain. $\boldsymbol{d}$ and $\boldsymbol{D}_{i}$ are, respectively, the observation vector and a synthetic vector of perturbations of observations $\boldsymbol{d}$ (here, ensemble average of $\boldsymbol{D}_{i}=0$ in DEnKF). $i$ is ensemble member. $\mathbf{H}$ is observation sensitivity matrix as a non-linear operator.

In EnKF, error covariance matrix $(P)$ is determined by model state ensemble $(X)$ as followed.

$\mathrm{A}_{i}=X_{i}-x$

where, $x=\frac{1}{m} \sum_{i=1}^{m} X_{i} . m$ is ensemble size. $X_{i}$ is ensemble member of model state.

$P=\frac{1}{m-1} \sum_{i=1}^{m}\left(X_{i}-x\right)\left(X_{i}-x\right)^{T}=\frac{1}{m-1} A A^{\mathrm{T}}$

Because of following relationships $A^{\mathrm{a}}=A^{\mathrm{f}}+K(D-$ $\left.\mathbf{H} A^{\mathrm{f}}\right) \cong A^{\mathrm{f}} K \mathbf{H} A^{\mathrm{f}}$ and $D=0, P^{\mathrm{f}} \mathbf{H}^{T} K^{T}=K \mathbf{H} P^{\mathrm{f}}$, then error covariance in Eq. (3-3) is rearranged as followed (Sakov et al., 2008).

$P^{\mathrm{a}}=P^{\mathrm{f}}-2 K \mathbf{H} P^{\mathrm{f}}+K \mathbf{H} P^{\mathrm{f}} \mathbf{H}^{T} K^{T}$

Here, if $K \mathbf{H}$ is negligibly small, analysis can be tuned for quadratic form $\left(K \mathbf{H} P^{\mathrm{f}} \mathbf{H}^{T} K^{T}\right)$ by approximation of $K=\frac{1}{2} K$ (Whitaker and Hamill, 2002). Accordingly, analysis error covariance and anomaly stated above become:

$A^{\mathrm{a}}=A^{\mathrm{f}}-\frac{1}{2} K \mathbf{H} A^{\mathrm{f}}\left(\right.$ where, $\left.A^{\mathrm{f}}=X^{\mathrm{f}}-x^{\mathrm{f}}\right)$

and

$P^{\mathrm{a}}=(1-K \mathbf{H}) P^{\mathrm{f}}+\frac{1}{4} K \mathbf{H} P^{\mathrm{f}} \mathbf{H}^{T} K^{T}$

To acquire model state ensemble pool, aerodynamic roughness height was randomly generated by the assumption of Gaussian distribution. For this, NDVI was perturbed, since aerodynamic roughness is propagated from NDVI as explained and designed in Sect. 2.2.1. Other meteorological inputs were assumed certain. Meteorological inputs were directly measured from a local BJ station, without a possibility affected by model structure error or atmospheric effect of a remote sensor. These parameters such as wind velocity, pressure, humidity or temperature are very straightforward 
in measurement, unlike indirect estimation in aerodynamic roughness height. Heat flux output ensemble pool was established by propagation from aerodynamic roughness input.

According to previous study (Moradkhani et al., 2005), Normalized RMSE ratio (NRR: time averaged RMSE over ensemble member averaged RMSE) was used to evaluate and quantify this randomly generated ensemble pool spread. Out of 20 trials (variance ranging from 8 to $50 \%$; ensemble size ranging from 20 to 100), a group of 1.05 of $^{N_{R R}}{ }^{\mathrm{H}}$ and 1.1 of $\mathrm{NRR}^{\mathrm{LE}}$ (ensemble size $=100$, variance $=30 \%$ ) was in acceptable range (cf. ideal NRR is a unity), and used in this study. Here, $\mathrm{NRR}^{\mathrm{H}}$ implies NRR for sensible heat while $\mathrm{NRR}^{\mathrm{LE}}$ means NRR for latent heat. Number of observation updated at each assimilation step was equivalent to number of model states. Inflation was set to 1.01 .

\section{Results}

\subsection{Data assimilation}

Only sensible heat EnKF final analysis was used to identify aerodynamic roughness via EnKF for various reasons. First, in general, it was considered that latent heat in arid area has a degree of uncertainty in measurement. It was suggested that vapour pressure gradient is vulnerable to measurement errors in arid area, since it is much smaller than temperature gradient on dry condition (Boulet et al., 1997; Jochum et al., 2006; Prueger et al., 2004; Weaver et al.,1990). This was also supported by energy budget analysis over the Tibetan Plateau, indicating that sensible heat is known as the dominant energy in ABL (Ma et al., 2009).

Second, in a SEBS model structure, as briefly described in Sect. 2.2, small error in sensible heat can be amplified or transfered to latent heat, because latent heat is calculated from the sensible heat estimated beforehand. Furthermore, Gaussian error propagation analysis was conducted to investigate the interactive interference between roughness parameters and each heat flux. This comparison showed that latent heat has a higher variance than sensible heat, being interfered by a larger number of roughness parameter errors including LAI, displacement height, or canopy height in addition to aerodynamic roughness itself (Marx et al., 2008). For various roughness inputs (with a mean of $0.035 \mathrm{~m}$ and standard deviation of $0.016 \mathrm{~m}$, ranging from 0.015 to $0.055 \mathrm{~m}$ ), variance of sensible and latent heat propagated by SEBS was estimated as 225 and $331\left[\mathrm{~W} \mathrm{~m}^{-2}\right]^{2}$. With regard to interference (each parameter was assumed to be independent), latent heat was affected by several other input errors (i.e. LAI, $h_{\mathrm{c}}, Z_{\mathrm{oh}}, d_{0}$ ) in addition to $Z_{\mathrm{om}}$, while sensible heat mostly affected by aerodynamic roughness height. In detail, variances for displacement height $\left(20931\left[\mathrm{~W} \mathrm{~m}^{-2}\right]^{2}\right)$, thermal roughness height $\left(663\left[\mathrm{~W} \mathrm{~m}^{-2}\right]^{2}\right)$, canopy height $\left(136\left[\mathrm{~W} \mathrm{~m}^{-2}\right]^{2}\right)$, and LAI $\left(100\left[\mathrm{~W} \mathrm{~m}^{-2}\right]^{2}\right)$ were reported for latent heat, while variance of canopy height (89 [W m $\left.{ }^{-2}\right]^{2}$ ) other than aerodynamic roughness was considered significant for sensible heat.

$$
\begin{gathered}
\delta_{\mathrm{LE}}^{2}=\left(\frac{\partial_{\mathrm{LE}}}{\partial_{Z_{\mathrm{om}}}}\right)^{2} \delta_{Z_{\mathrm{om}}}^{2}+\left(\frac{\partial_{\mathrm{LE}}}{\partial_{\mathrm{LAI}}}\right)^{2} \delta_{\mathrm{LAI}}^{2}+\left(\frac{\partial_{\mathrm{LE}}}{\partial_{h_{\mathrm{c}}}}\right)^{2} \\
\delta_{h_{\mathrm{c}}}^{2}+\left(\frac{\partial_{\mathrm{LE}}}{\partial_{Z_{\mathrm{oh}}}}\right)^{2} \delta_{Z_{\mathrm{oh}}}^{2}+\left(\frac{\partial_{\mathrm{LE}}}{\partial_{\mathrm{d}_{0}}}\right)^{2} \delta_{\mathrm{d}_{0}}^{2} \\
\delta_{\mathrm{H}}^{2}=\left(\frac{\partial_{\mathrm{H}}}{\partial_{Z_{\mathrm{om}}}}\right)^{2} \delta_{Z_{\mathrm{om}}}^{2}+\left(\frac{\partial_{\mathrm{H}}}{\partial_{h_{\mathrm{c}}}}\right)^{2} \delta_{h_{\mathrm{c}}}^{2}
\end{gathered}
$$

Accordingly, sensible heat was selected to be a more direct indicator for aerodynamic roughness height estimation.

After assimilation, as shown in Fig. 3, RMSE between Ensemble Kalman Filter - analysed sensible heat and observation was successfully improved to $17 \mathrm{~W} \mathrm{~m}^{-2}\left(65 \mathrm{~W} \mathrm{~m}^{-2}\right.$ : open-loop). Data point holding a large discrepancy with observation (i.e. to discard $x_{\mathrm{t}}^{\mathrm{a}}$ if $\left|x_{\mathrm{t}}^{\mathrm{a}}-H_{\mathrm{breb}}\right|>10 \mathrm{~W} \mathrm{~m}^{-2}$ ) was excluded, when it was inversely tracked back to initial $Z_{\mathrm{om}}$ ensemble pool as shown in following parameter estimation (Sect. 3.2).

\subsection{Parameter estimation}

Based upon previous Gaussian error propagation analysis that demonstrated relatively less interfered and exclusive relationship between sensible heat flux and roughness parameters, aerodynamic roughness input ensemble members corresponding to sensible heat EnKF final analysis were found from ensemble pool. This ensemble member was considered the very approximate roughness parameter that produced EnKF final analysis. During pre-Monsoon period of highly unstable and free convective time that sensible heat is much greater than latent heat, only daytime unstable sensible heat flux ( $>150 \mathrm{~W} \mathrm{~m}^{-2}$ ) was used to estimate aerodynamic roughness (Prueger et al., 2004; de Bruin and Verhoef, 1997). Next, since aerodynamic roughness height is usually scattered with a high standard deviation (Yang et al., 2008), this study selected only the values the most frequently found in ensemble member candidates. In Fig. 4, for example, on day of year $132, Z_{\mathrm{om}}$ of $0.003 \mathrm{~m}$ on $\mathrm{x}$-axis was the most frequent (the highest number on y-axis) so that this number was adopted as aerodynamic roughness height on day of year 132, while $Z_{\mathrm{om}}$ of $0.015 \mathrm{~m}$ on $\mathrm{x}$-axis was the most frequent (the highest number on $y$-axis) so that this number was assigned as aerodynamic roughness height on day of year 163 (Yang et al., 2008).

As shown in Fig. 5, resultant aerodynamic roughness height reflected the vegetation effects being consistent with the NDVI and LAI patterns and the bare soil condition in the beginning of this experimental period. Time- variant roughness showed a mean of $0.0098 \mathrm{~m}$, and standard deviation of $0.0063 \mathrm{~m}$, and range of minimum $(0.0029 \mathrm{~m})$ and maximum $(0.0186 \mathrm{~m})$. This estimate was consistent with fixed literature value for grasslands (0.01 m: Beljaars et al., 1983), but time 


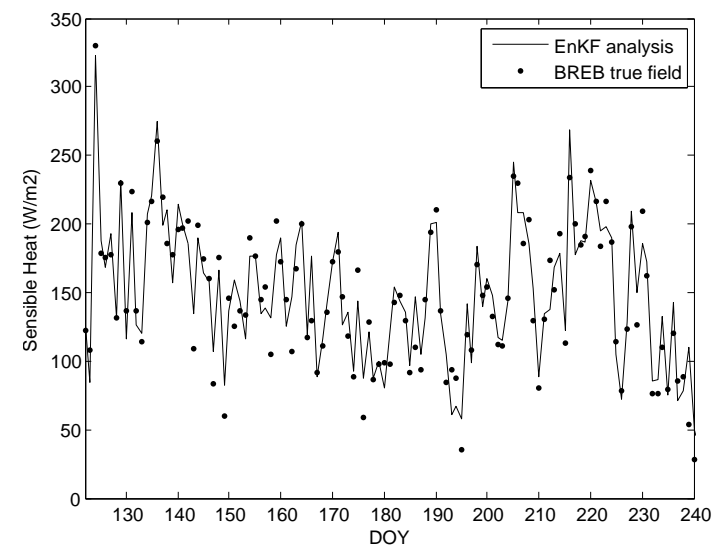

Fig. 3. Daily average sensible heat estimated by EnKF final analysis and true field $\left(\mathrm{RMSE}=17 \mathrm{~W} \mathrm{~m}^{-2}\right.$ ).
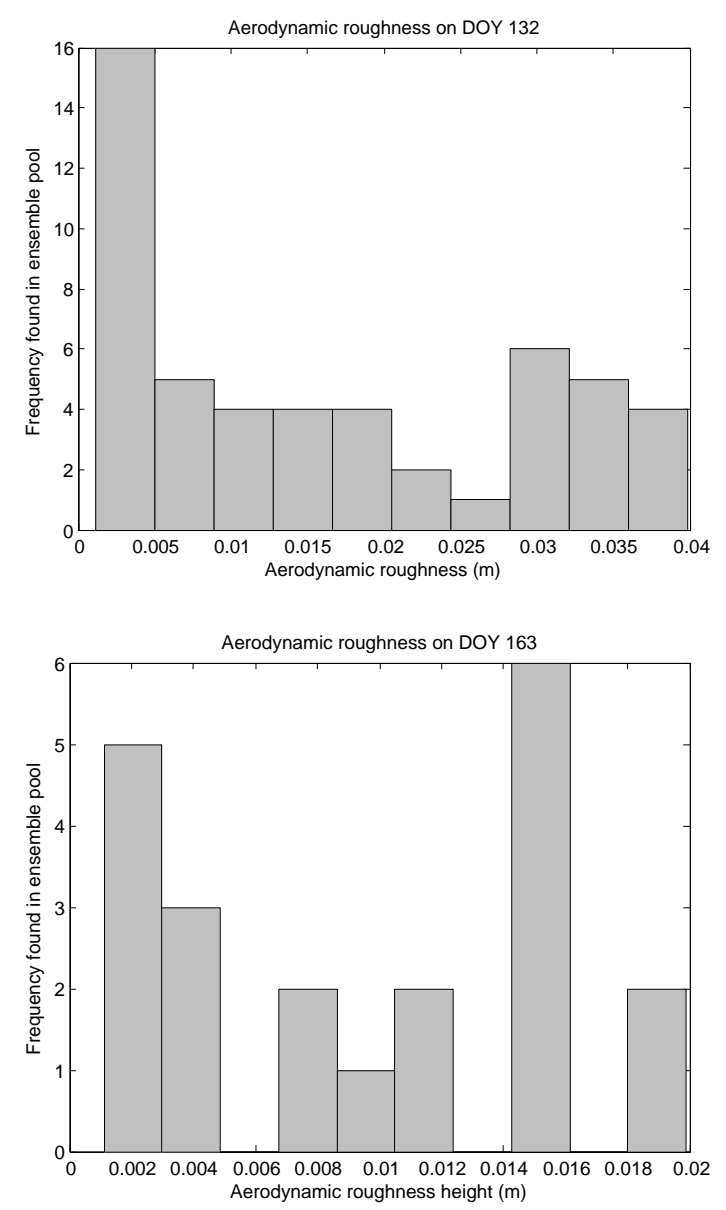

Fig. 4. Frequency of aerodynamic roughness on different days.

variant. This was also agreeable with previous study carried out with eddy covariance data over the Naqu site (Sun, 1999; Yang et al., 2003).

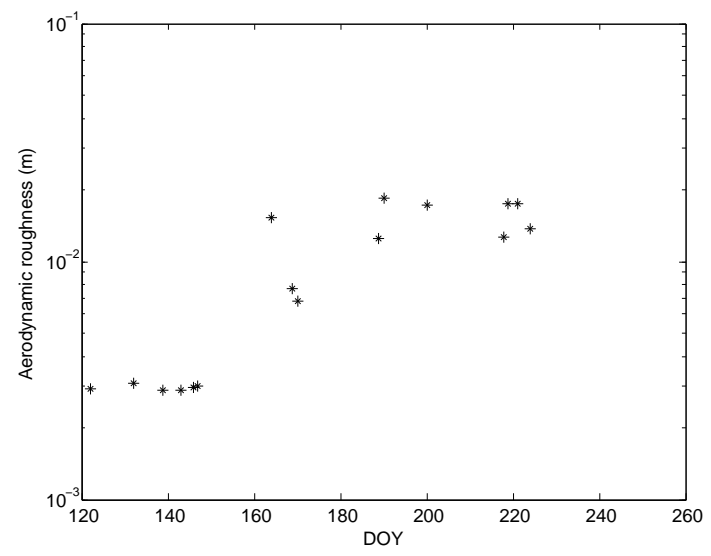

Fig. 5. Aerodynamic roughness height inversely tracked via EnKF.

\subsection{Validation with heat flux outputs}

Aerodynamic roughness height input found from sensible heat EnKF final analysis was inserted into original SEBS to examine its influence over heat flux estimation and energy source partitioning. Improvement of heat flux estimates via this calibration was found especially on wet condition. A large discrepancy among original SEBS model estimates, observation and estimation of this study was found around day of year 180 during the summer Monsoon period, as shown in Fig. 6. Here, original SEBS estimate was considered biased by incorrect estimation of aerodynamic roughness input (Fig. 1). BREB observation also could contain some degree of uncertainty stemming from assumption of energy balance closure. However, it was considered that the error of original SEBS before calibration of roughness parameter was considered bigger than a BREB approach. This is because, as shown in Sect. 2.1, several uncertain BREB estimates were already filtered out by five parsimonious criteria. In addition, BREB estimates were validated with eddy covariance data obtained previously (van der Velde et al., 2009). To avoid using uncertain data, only sensible heat was used for data assimilation and calibration, considering dry climate in this experimental site. Finally, considering an increase in precipitation and surface soil moisture during Monsoon period as demonstrated in Fig. 7,latent heat estimates higher than original SEBS were considered plausible, suggesting that approach in this study successfully exhibited intermediate numbers between original SEBS and BREB especially during Monsoon period ( $\mathrm{Li}$ et al., 2010; Margulis et al., 2002). Here, soil texture is less likely to interfer with evaporation, because soil texture in given site is known as loamy sand, not clay than might be able to prevent latent heat activity. Thus, it was concluded that heat flux estimation especially during the Monsoon period was improved.

In detail, as shown in Fig. 6, newly estimated aerodynamic and thermal roughness $\left(0.1 \cdot Z_{\mathrm{om}}\right.$ by approximation $)$ reported better RMSE $\left(H: 34 \mathrm{~W} \mathrm{~m}^{-2}\right.$, LE: $\left.40 \mathrm{~W} \mathrm{~m}^{-2}\right)$ with 
BREB heat flux observation than original SEBS RMSE ( $H$ : $65 \mathrm{~W} \mathrm{~m}^{-2}$, LE: $\left.60 \mathrm{~W} \mathrm{~m}^{-2}\right)$. Here, RMSE $\left(34 \mathrm{~W} \mathrm{~m}^{-2}\right)$ in sensible heat was found to be slightly higher than the ensemble Kalman final analysis previously reported in Fig. 3 (RMSE: $17 \mathrm{~W} \mathrm{~m}^{-2}$ ), because precedent values on previous time step were assigned when no optimal aerodynamic parameter (as Not A Number) was found in a given time step.

There are also various explanations for RMSE in latent heat (RMSE: $40 \mathrm{~W} \mathrm{~m}^{-2}$ ). First, Gaussian error propagation analysis has previously shown that latent heat is affected by several other roughness input parameter errors. In addition, small error in sensible heat can be propagated to latent heat through SEBS model. In detail, overestimated thermal or aerodynamic roughness height in original SEBS led to overestimated actual sensible heat $(H)$ by following Eq. (4) below or underestimated aerodynamic resistance $\left(r_{\mathrm{a}}\right)$ by Eq. (2$10)$ or over-estimated wet sensible heat $\left(H_{\text {wet }}\right)$ by Eq. (2-9) (Su, 2005).

$$
\begin{aligned}
T_{\text {sur }}-T_{\text {air }} & =\frac{H}{k U^{*} \rho_{\text {air }} C_{\mathrm{p}}}\left[\ln \left(\frac{z-d_{0}}{z_{\mathrm{oh}}}\right)-\Psi_{\mathrm{h}}\left(\frac{z-d_{0}}{L}\right)\right. \\
& \left.+\Psi_{\mathrm{h}}\left(\frac{z_{\mathrm{oh}}}{L}\right)\right]
\end{aligned}
$$

where, $T_{\text {sur }}$ and $T_{\text {air }}$ are potential temperature for land surface and air at the reference height. $\psi_{\mathrm{h}}$ is stability correction function for sensible heat transfer, and $L$ is Obukhov length (Su, 2005).

Overestimated sensible heat could further give a rise to underestimated relative evaporation $(\Lambda r)$ by Eq. (2-7), and evaporative fraction $(\Lambda)$ by Eq. (2-6), and finally latent heat by Eq. (2-5). This underestimated latent heat and overestimated sensible heat by roughness errors was demostrated in Fig. 6 (original SEBS), while overestimated aerodynamic roughness by original SEBS was shown in Fig. 1.

A dominant energy in the Tibetan Plateu is known as sensible heat (Ma et al., 2009). However, this study anticipated some change in energy partioning by vegetaion development and elevated soil moisture during Monsoon (van der Tol et al., 2009). By calibration in this study, it was possible to reasonably capture this change in energy partitioning during Monsoon period. It was found that latent heat flux was approximately comparable to sensible heat during Monsoon, suggesting both latent heat and sensible heat contributed to energy source. It was thought that high sensible heat (above $150 \mathrm{~W} \mathrm{~m}^{-2}$ ) developed convective activities in atmospheric boundary layer (ABL) before Monsoon period, resulting in Monsoon precipitation as a feedback (Ma et al., 2009; Wen et al., 2010). This Monsoon precipitation further elevated surface soil moisture (reached up to $0.3 \mathrm{~m}^{3} \mathrm{~m}^{-3}$ during Monsoon, and dropped down to $0.05 \mathrm{~m}^{3} \mathrm{~m}^{-3}$ after Monsoon in Fig. 7). This indirectly increased latent heat again, but slightly suppressed sensible heat during Monsoon, suggesting some positive correlationship between surface soil moisture and latent heat under given condition - i.e. temperature, soil texture, vegetation, available surface soil moisture level (dryness) and a frequency and quantity of Monsoon precipitaiton (Li et al., 2010; Margulis et al., 2002).

Another validation was carried out with eddy covariance data over maize field at Landriano station, in Italy during vegetation proliferation period (the beginning of July to the middle of October), where atmospheric condition is mostly unstable, and soil moisture is moderately high $(0.25 \sim 0.35)$ (Baroni et al., 2010). Unlike previous BREB data in arid condition, it was considered that both latent and sensible heat fluxes made a contribution to uncertainty (to the same extent, $15 \sim 20 \%$ for both, Chavez et al., 2005) under wet condition. Accordingly, both heat fluxes were assimilated by EnKF. For a comparison, aerodynamic roughness formulated as a function of LAI and drag force by Olioso et al. (2002) showed a mean of $0.32 \mathrm{~m}$. One determined by a traditional wind profile method including atmospheric stability correction on both neutral and non-neutral condition reported a mean of $0.18 \mathrm{~m}$ (Ma et al., 2008). Aerodynamic roughness inversely tracked from heat flux EnKF final analysis illustrated an intermediate value of $0.25 \mathrm{~m}$ as a mean and $0.04 \mathrm{~m}$ as standard deviation.

\section{Conclusions}

In heat flux estimation, aerodynamic roughness is a major uncertain input. Unlike other parameters such as pressure, land surface temperature or surface soil moisture, this parameter can be indirectly estimated using eddy covariance data, which covers only limited fetch size on a local scale. However, due to measurement errors or some land surface-atmospheric conditions not satisfying MOS assumptions, data are often inclined to be scattered with high standard variations. In a larger scale, a method using remotely sensed vegetation index can be employed. However, this still requires drag force input obtained from eddy covariance data, and also can be applied to limited vegetation type, on account of saturation problem of remote sensing. Non-linear MOS equations are also used to estimate aerodynamic roughness by iteration. However, this is a complicated procedure requiring the accuracy of several other related parameters involved in MOS theory.

Thus, this study demonstrated a simpler operational framework to retrieve a parameter of aerodynamic roughness via EnKF that affords non-linearity. This method demands only single or two heat flux, depending on climatic characteristics on site, instrument error and model error structure analysis. This study successfully adjusted the heat flux outputs previously over or underestimated by original SEBS, allowing more reliable interpretation for energy partitioning and water cycle. Although sensible heat is a dominant energy, latent heat was comparable to sensible heat during Monsoon. Aerodynamic roughness estimated in this study was timevariant, reflecting vegetation effects, and relatively independent from remotely sensed VI saturation problem. This approach can be applied to region where eddy covariance data 

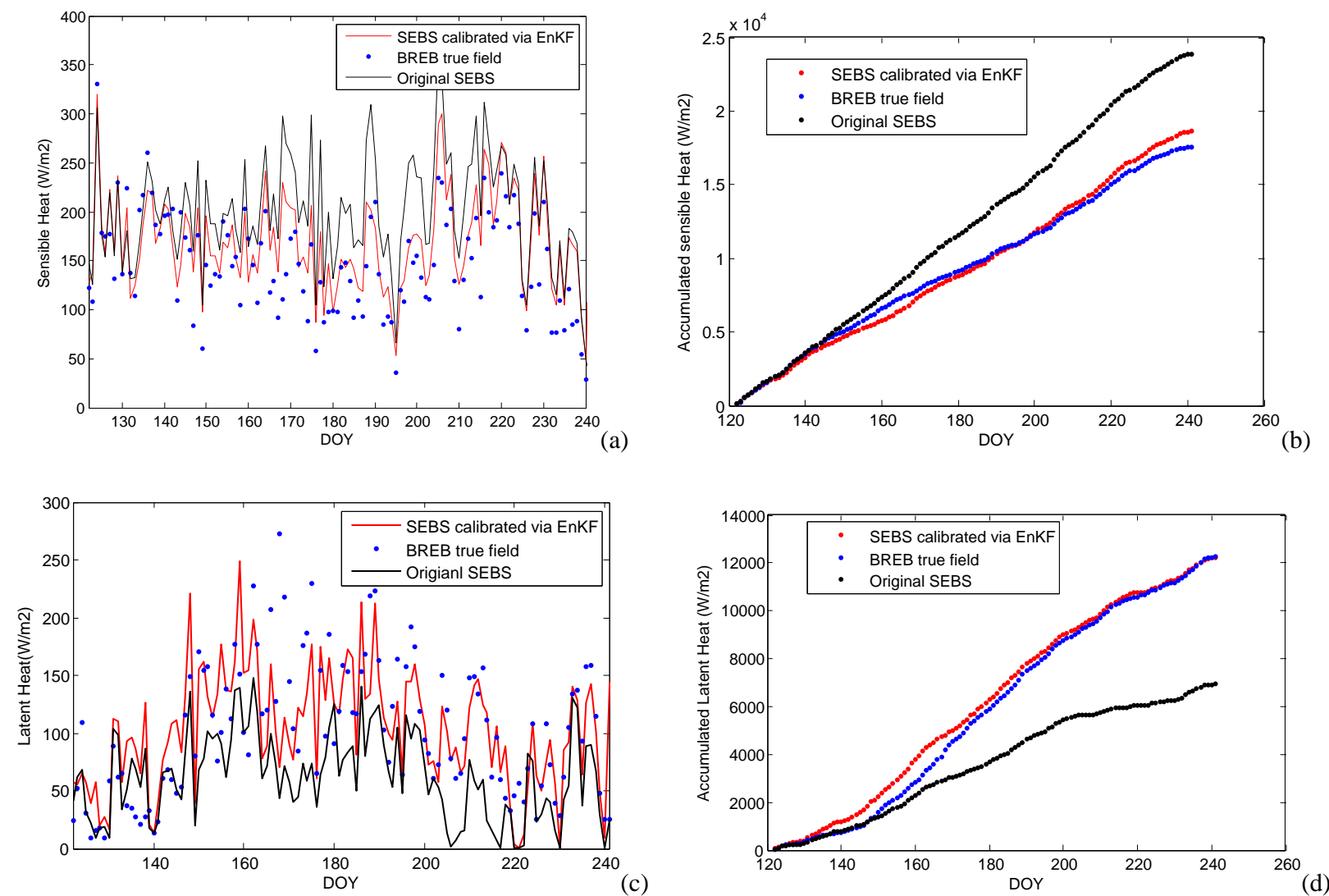

Fig. 6. Comparison in heat flux estimates: (a) sensible heat, (b) accumulated sensible heat, (c) latent heat, and (d) accumulated latent heat.

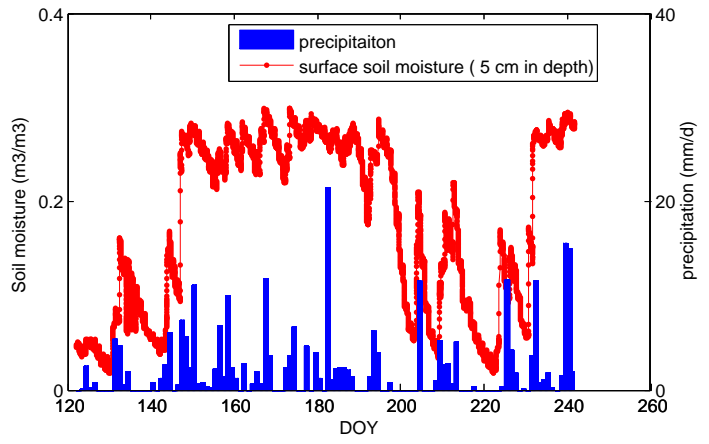

Fig. 7. Seasonal change in surface soil moisture measured at $5 \mathrm{~cm}$ in depth and rainfall estimated by Chinese meteorological office. Soil moisture measurement method was described by previous publication (van der Velde et al., 2009).

are not available. This may replace existing wind profile or vegetation index approach as an alternative. Future work will include some scale issues: the application of this approach to a larger scale with heterogeneity. The forest area where it is difficult to identify the vertical characteristics with remotely sensed VIs is also an interest. Effect of observation update regime - e.g. in case of satellite data with low temporal frequencies - may be explored in future data assimilation study.
Acknowledgements. We give special thanks to Pavel Sakov who provided ensemble Kalman Filter algorithm and van der Velde and Zeyong $\mathrm{Hu}$ for meteorological data over Naqu site, as well as Giovanni Ravazzani who supported this study in the framework of the "ACQWA EU/FP7" project (grant number 212250) "Assessing Climate impacts on the Quantity and quality of WAter". We are grateful to the reviewers and editors for constructive comments to improve this manuscript.

Edited by: E. Toth

\section{References}

Baroni, G., Facchi, A., Gandolfi, C., Ortuani, B., Horeschi, D., and van Dam, J. C.: Uncertainty in the determination of soil hydraulic parameters and its influence on the performance of two hydrological models of different complexity, Hydrol. Earth Syst. Sci., 14, 251-270, doi:10.5194/hess-14-251-2010, 2010.

Beljaars, A. C. M., Schotanus, P., and Nieuwstadt, F. T. M.: Surface layer similarity under nonuniform fetch conditions, J. Clim. Appl. Meteorol., 22, 1800-1810, 1983.

Boulet, G. , Braud, I., and Vauclin, M.: Study of the mechanisms of evaporation under arid conditions using a detailed model of the soil-atmosphere continuum, J. Hydrol., 193, 114-141, 1997. 
Chavez, J. L., Neale, C. M. U., Hipps, L. E., Prueger, J. H., and Kustas, W. P.: Comparing aircraft-based remotely sensed energy balance fluxes with eddy covariance tower data using heat flux source area functions, J. Hydrometeorol., 66, 923-940, 2005.

Chen, R. K. and Yang, C. M.: Determining the Optimal Timing for Using LAI and NDVI to Predict Rice Yield, J. Photogramm. Remote Sens., 103, 239-254, 2005.

Chen, Y., Yang, K., Zhou, D., Qin, J., and Guo, X.: Improving the Noah Land Surface Model in Arid Regions with an Appropriate Parameterization of the Thermal Roughness Length. J. Hydrometeorol., 11, 995-1006. doi:10.1175/2010JHM1185.1, 2010.

Choi, T., Kim, J., Lee, H., Hong, J., Asanuma, J., Ishikawa, H., Gao, Z., Wang, J., and Koike, T.: Turbulent exchange of heat, water vapor, and momentum over a Tibetan prairie by eddy covariance and flux variance measurements, J. Geophys. Res., 109, D21106, doi:10.1029/2004JD004767, 2004.

Choudhury, B. J. and Monteith, J. L.: A four-layer model for the heat budget of homogeneous land surfaces, Q. J. Roy. Meteorol. Soc., 114, 373-398, 1988.

De Bruin, H. A. R. and Verhoef, A.: A new method to determine the zero-plane displacement, Bound.-Lay. Meteorol., 82, 159-164, 1997.

Dunne, S. and Entekhabi, D.: An ensemble-based reanalysis approach to land data assimilation, Water Resour. Res., 41, W02013, doi:10.1029/2004WR003449, 2005.

Evensen, G.: Sampling strategies and square root analysis schemes for the EnKF, Ocean Dynam., 54, 539-560, 2004.

Foken, T. H. and Wichura, B.: Tools for quality assessment of surface-based flux measurements, Agr. Forest. Meteorol., 78, 83$105,1996$.

Goegebeur, M. and Pauwels, V. R. N.: Improvement of the PEST parameter estimation algorithm through Extended Kalman Filtering, J. Hydrol., 337, 436-451. 2007.

Jochum, M. A. O., de Bruin, H. A. R., Holtslag, A. A. M., and Belmonte, A. C.: Area-Averaged Surface Fluxes in a Semiarid Region with Partly Irrigated Land Lessons Learned from EFEDA, J. Appl. Meteorol. Clim., 45, 856-874, 2006.

Kohsiek, W., de Bruin, H. A. R., The, H., and van den Hurk, B.: Estimation of the sensible heat flux of a semi-arid area using surface radiative temperature measurements, Bound.-Lay. Meteorol., 63, 213-230, 1993.

Li, F., Crow, W. T., and Kustas, W. P.: Towards the estimation rootzone soil moisture via the simultaneous assimilation of thermal and microwave soil moisture retrievals, Adv. Water Resour., 33, 201-214, 2010

Liu, H. and Foken, T.: A modified Bowen ratio method to determine sensible and latent heat fluxes, Meteorol. Z., 10, 71-80, 2001.

Liu, S., Li, S.-G., Yu, G.-R., Sun, X.-M., Zhang, L.-M., Hu, Z.-M., Li, Y.-N., and Zhang, X.-Z.: Surface energy exchanges above two grassland ecosystems on the Qinghai-Tibetan Plateau, Biogeosciences Discuss., 6, 9161-9192, doi:10.5194/bgd-6-9161-2009, 2009.

Lu, H., Koike, T., Yang, K., Hu, Z., Xu, X., Rasmy, M., Kuria, D., and Tamagawa, K.: Improving land surface soil moisture and energy flux simulations over the Tibetan plateau by the assimilation of the microwave remote sensing data and the GCM output into a land surface model, Int. J. Appl. Earth Observ. Geoinf., 17, 4354, 2012.
Ma, J. and Daggupaty, S. M.: Using All Observed Information in a Variational Approach to Measuring $Z_{\mathrm{om}}$ and $Z_{0 \mathrm{t}}$, Am. Meteorol. Soc., 1391-1401, 1999.

Ma, Y., Tsukamoto, O., Wang, J., Ishikawa, H., and Tamagawa, I.: Analysis of aerodynamic and thermodynamic parameters over the grassy marshland surface of Tibetan Plateau, Prog. Nat. Sci., 121, 36-40, 2002.

Ma, Y., Fan, S., Ishikawa, H., Tsukamoto, O., Yao, T., Koike, T., Zuo, H., Hu, Z., and Su, Z.: Diurnal and inter-monthly variation of land surface heat fluxes over the central Tibetan Plateau area, Theor. Appl. Climatol., 80, 259-273, 2005.

Ma, Y., Menenti, M., Feddes, R., and Wang, J.: Analysis of the land surface heterogeneity and its impact on atmospheric variables and aerodynamic and thermodynamic roughness lengths, J. Geophys. Res., 113, D08113, doi:10.1029/2007JD009124, 2008.

Ma, Y., Wang, Y., Wu, R., Hu, Z., Yang, K., Li, M., Ma, W., Zhong, L., Sun, F., Chen, X., Zhu, Z., Wang, S., and Ishikawa, H.: Recent advances on the study of atmosphere-land interaction observations on the Tibetan Plateau, Hydrol. Earth Syst. Sci., 13, 1103-1111, doi:10.5194/hess-13-1103-2009, 2009.

Margulis, S. A., McLaughlin, D., Entekhabi, D., and Dunne, S.: Land data assimilation and estimation of soil moisture using measurements from the Southern Great Plains 1997 Field Experiment, Water Resour. Res., 38, 1299, doi:10.1029/2001WR001114, 2002.

Marx, A., Kunstmann, H., Schuttemeyer, D., and Moene, A. F.: Uncertainty analysis for satellite derived sensible heat fluxes and scintillometer measurements over Savannah environment and comparison to mesoscale meteorological simulation results, Agr. Forest Meteorol., 148, 656-667, 2008.

Massman, W. J.: An analytical one-dimensional model of momentum transfer by vegetation of arbitrary structure, Bound.-Lay. Meteorol., 83, 407-421, 1997.

Montaldo, N., Albertson, J. D., Mancini, M., and Kiely, G.: Robust simulation of root-zone soil moisture with assimilation of surface soil moisture data, Water Resour. Res., 37, 2889-2900, 2001.

Montaldo, N., Albertson, J. D., and Mancini, M.: Dynamic Calibration with an Ensemble Kalman Filter Based Data Assimilation Approach for Root-Zone Moisture Predictions, J. Hydrometeorol., 8, 910-921, doi:10.1175/JHM582.1, 2007.

Moradkhani, H., Sorooshian, S., Gupta, H. V., and Houser, P. R.: Dual state-parameter estimation of hydrological models using ensemble Kalman filter, Adv. Water Resour., 28, 135-147, 2005.

Ohmura, A.: Objective criteria for rejecting data for Bowen ratio flux calculations, Am. Meteorol. Soc., 21, 595-598, 1982.

Olioso, A., Jacob, F., Hadjar, D., Lecharpentier, P., and Hasager, C. B.: Spatial distribution of evapotranspiration and aerodynamic roughness from optical remote sensing, in: Proceedings of the International Workshop on Landscape Heterogeneity and Aerodynamic Roughness: Modelling and Remote Sensing Perspectives, 12 October 2001, edited by: Debie, H. and de Ridder K., Antwerp, Belgique, VITO, 19-26, 2002.

Pauwels, V. R. N., Balenzano, A., Satalino, G., Skriver, H., Verhoest, N. E. C., and Mattia, F.: Optimization of Soil Hydraulic Model Parameters Using Synthetic Aperture Radar Data: An Integrated Multidisciplinary Approach, IEEE T. Geosci. Remote, 47, 455-467, doi:10.1109/TGRS.2008.2007849, 2009. 
Perez, P. J., Castellvi, F., Ibañez, M., and Rosell, J. I.: Assessment of reliability of Bowen ratio method for partitioning fluxes, Agr. Forest Meteorol., 97, 141-150, 1999.

Prueger, J. H., Kustat, W., Hipps, L. E., and Hatfield. J. L.: Aerodynamic parameters and sensible heat flux estimates for a semi-arid ecosystem, J. Arid Environ., 57, 87-100, 2004.

Reichle, H. R.: Data assimilation methods in the Earth sciences, Adv. Water Resour., 31, 1411-1418, 2008.

Reichle, R. H., McLaughlin, D. H., and Entekhabi, D.: Hydrologic Data Assimilation with the Ensemble Kalman Filter, Mon. Weather Rev., 130, 103-114, doi:10.1175/15200493(2002)130<0103:HDAWTE>2.0.CO;2, 2002.

Richter, K. and Timmermans, W. J.: Physically based retrieval of crop characteristics for improved water use estimates, Hydrol. Earth Syst. Sci., 13, 663-674, doi:10.5194/hess-13-663-2009, 2009.

Sakov, P. and Oke, P. R.: A deterministic formulation of the ensemble kalman filter:an alternative to ensemble sqaure root filters, Tellus A, 60, 361-371, 2008.

Scanlon, T. M., Albertson, J. D., and Kustas, W. P.: Scale effects in estimating large eddy-driven sensible heat fluxes over heterogenous terrain, in: Remote sensing and Hydrology 2000, IAHS Publ. no. 267, Proceedings of a symposium held at Santa Fe, April 2000, Santa Fe, USA, 2001.

$\mathrm{Su}, \mathrm{Z}$. : The Surface Energy Balance System (SEBS) for estimation of turbulent heat fluxes, Hydrol. Earth Syst. Sci., 6, 85-100, doi:10.5194/hess-6-85-2002, 2002.

$\mathrm{Su}, \mathrm{Z}$.: Estimation of the Surface Energy Balance. Encyclopedia of Hydrological Sciences, John Wiley \& Sons, Ltd., 2005.

Su, Z., Schmugge, T., Kustas, W. P., and Massman, W. J.: An evaluation of two models for estimation of the roughness height for heat transfer between the land surface and the atmosphere, J. Appl. Meteorol., 40, 1933-1951, 2001.

Sun, F., Ma, Y., Ma, W., and Li, M.: One observational study on atmospheric boundary layer structure in Mt. Qomolangma region, Plateau Meteorol., 256, 1014-1019, 2006.

Sun, F., Ma, Y., Li, M., Ma, W., Tian, H., and Metzge, S.: Boundary layer effects above a Himalayan valley near Mount Everest, Geophys. Res. Lett., 34, L08808, doi:10.1029/2007GL029484, 2007.

Sun, J.: Diurnal variations of thermal roughness height over a grassland, Bound.-Lay. Meteorol., 92, 407-427, 1999.

Timmermans, J., van der Tol, C., Verhoef, A., Verhoef, W., Su, Z., van Helvoirt, M., and Wang, L.: Quantifying the uncertainty in estimates of surface-atmosphere fluxes through joint evaluation of the SEBS and SCOPE models, Hydrol. Earth Syst. Sci. Discuss., 8, 2861-2893, doi:10.5194/hessd-8-2861-2011, 2011.
Tsuanga, B. J., Tsaia, J. L., Lina, M. D., and Chen, C. L.: Determining aerodynamic roughness using tethersonde and heat flux measurements in an urban area over a complex terrain, Atmos. Environ., 37, 1993-2003, 2003.

van der Tol, C., van der Tol, S., Verhoef, A., Su, B., Timmermans, J., Houldcroft, C., and Gieske, A.: A Bayesian approach to estimate sensible and latent heat over vegetated land surface, Hydrol. Earth Syst. Sci., 13, 749-758, doi:10.5194/hess-13-7492009, 2009.

van der Velde, R.: Soil moisture remote sensing using active microwaves and land surface modeling, Ph.D. thesis, ITC dissertation number 176, ITC, Enschede, The Netherlands, 2010.

van der Velde, R., Su, Z., Ek, M., Rodell, M., and Ma, Y.: Influence of thermodynamic soil and vegetation parameterizations on the simulation of soil temperature states and surface fluxes by the Noah LSM over a Tibetan plateau site, Hydrol. Earth Syst. Sci., 13, 759-777, doi:10.5194/hess-13-759-2009, 2009.

Weaver, H. L.: Temperature and humidity flux-variance relations determined by one-dimensional eddy correlation, Bound.-Lay. Meteorol., 53, 77-91, 1990.

Wen, L., Cui, P., Li, Y., Wang, C., Liu, Y., Chen, N., and Su, F.: The influence of sensible heat on Monsoon precipitation in central and eastern Tibet, Meteorol. Appl., 17, 452-462, 2010.

Whitaker, J. S. and Hamill, T. M.: Ensemble data assimilation without perturbed observations, Mon. Weather Rev., 132, 1590-1605, 2002.

Wieringa, J.: Updating the Davenport roughness classification, J. Wind Eng. Ind. Aerodyn., 41-44, 357-368, 1992.

Yang, K., Koike, T., and Yang, D.: Surface flux parameterization in the Tibetan plateau, Bound.-Lay. Meteorol., 116, 245-262, 2003.

Yang, K., Koike, T., Ishikawa, H., Kim, J., and Li, X.: Turbulent flux transfer over bare-soil surfaces: Characteristics and parameterization, J. Appl. Meteorol. Clim., 47, 276-290, doi:10.1175/2007JAMC1547.1, 2008.

Yang, P., Chen, Z., Zhou, Q., Zha, Y., Wu, W., and Shibasaki, R.: Comparisons of MODIS LAI products and LAI estimates derived from Landsat TM, Geoscience and Remote Sensing Symposium, IEEE International Conference on 31 July 2006-4 August 2006, 2681-2684, doi:10.1109/IGARSS.2006.692, 2006.

Yao, Y., Liu, Q., Liu, Q., and Li, X.: LAI retrieval and uncertainty evaluations for typical low-planted crops at different growth stages, Remote Sens. Environ., 112, 94-106, 2008.

Zeng, X. and Wang, A.: Consistent Parameterization of Roughness Length and Displacement Height for Sparse and Dense Canopies in Land Models, J. Hydrometeorol., 8, 730-737, doi:10.1175/JHM607, 2007. 